\title{
Antropología y colonialismo interno. David J. Guzmán, entre "poder supremo" y "capital"
}

Rafael Lara-Martínez

\author{
"La ciencia asociada con el capital está al abrigo de toda contingencia. Todo lo \\ supera el capital y la ciencia."
}

Anales del Museo Nacional, No 3, septiembre 1 de 1903: 118.

\section{Introducción}

Mientras en México, Europa y EE. UU. se cuestionó el manejo ideológico de las ciencias sociales, en El Salvador aún no se discute con amplitud la sumisión del saber positivo a designios políticos y financieros nacionales. Sabemos que la crítica no la inició el radicalismo de los sesenta. Anticipando dudas de toda una generación, el iniciador de la antropología estadounidense y contribuyente a la mexicana, Franz Boas (1858-1942), denunció el servicio político de la ciencia a los intereses imperiales de su propio país.

Lo que en Europa y EE. UU. cobraba un sentido de crítica al colonialismo, en México se percibía como colonialismo interno. Los países independientes no suprimieron los actos coloniales. En cambio, sustituyeron el centro rector, el cual - en vez de situarse en metrópolis de ultramar - lo localizaron en las nuevas capitales y gobiernos centrales dominados por grupos criollos y mestizos.

Más que ciencia objetiva, la antropología era modalidad del poder político hegemónico. Estudiaba la historia y actualidad de las "otras culturas" para someterlas al beneficio económico del Estado y de un grupo étnico particular. 
Se trataba de imponerles explotación comercial de recursos naturales y humanos a todas las naciones, lo cual se justificaba en términos de progreso por el mercado global.

Para ello, según preceptos salvadoreños, era necesario reconducir la educación integral de los países hacia rumbos pedagógicos y técnicos inexistentes. Por una "educación nacional práctica", habría que "ensanchar los estudios universitarios para obtener industriales, agrónomos y mecánicos diplomados en vez de títulos universitarios que pretenden formar la parte dirigente de nuestra sociedad [...] teóricos sin ocupación ni beneficio" (Anales, I.2., agosto/1903: 39). Efectivamente, el saber científico debería sustituir ideología de cuartel y pasión poética, ambas improductivas.

A inicios del siglo XXI, no nos preguntamos si en El Salvador ocurrió una utilización ideológica similar de la ciencia, en provecho de una minoría política, financiera y racial dominante. Nos sorprendería que, por "justicia poética", en el país se lograra una aplicación equitativa del conocimiento y su diseminación educativa general. En cambio, la cuestión por dilucidar ilustra la manera peculiar en que la racionalidad se volvía política encubierta, es decir, reincidía en la misma esfera de "pasión y ambición" que anhelaba reemplazar (L. R., Anales, I.1, julio/1903: 2). Para demostrar este capítulo olvidado, de escombros polvorientos de bibliotecas extranjeras, rescatamos la fundación del Museo Nacional (1903). Su constitución nos revelaría una idea de la ciencia que justificaba el quehacer ideológico de una generación. Creencias generalizadas argüían que innovaban una política progresista y liberal fundada en modelos objetivos y cuantificables.

Por esta labor de arqueología del pensamiento excavamos los principios fundacionales de la antropología salvadoreña y de su órgano máximo de expresión, el Museo Nacional, luego Museo Dr. "David J. Guzmán”, y ahora Museo Nacional de Antropología "David J. Guzmán” (Muna). Primero, el artículo indaga la manera en que el "órgano oficial" del museo sometía todo saber objetivo a su valor comercial. En seguida, expone la dinámica entre lo propio y lo ajeno que volcaba la identidad nacional hacia la imitación de lo extraño. Luego, desglosa la visión que ese mismo "órgano oficial" proyectaba de la mujer y del indígena como destinada al hogar, la primera, y a la desaparición, el segundo. Por último, explicita el ideal demográfico de Guzmán, el cual sugería importar población europea del Mediterráneo para completar el progreso y modernización del país. 
De estas cuatro aristas - saber utilitario, identidad sometida a lo ajeno, exclusión de la mujer y del indígena, inmigración neocolonial- demuestran la dificultad de la reflexión antropológica salvadoreña por dialogar con la diversidad étnica nacional. No nos asombra que su ideario no instaurara instituciones indigenistas que le concedieran derecho a la palabra y expresión cultural. Así mismo, el despliegue museográfico de sus resultados pretendía crear espacios urbanos de distinción social - para "público selecto" - y comercialización de productos, más que abrir el razonamiento intercultural entre sectores sociales dispersos.

\section{David J. Guzmán y los Anales del Museo Nacional}

Tal cual lo expresa el epígrafe inicial, resulta evidente que el fundador del Museo Nacional de Ciencias Naturales, Agrícolas, Artes Industriales, Comercio Nacional y Exterior (1903) y editor de los Anales, órgano oficial del instituto del mismo nombre (1903-1911), David J. Guzmán (1846-1927), no creía en la neutralidad desinteresada y objetiva de las ciencias naturales. Por lo contrario, antropología, botánica, geología, sismología, zoología, etc., obedecían a dictados de la "suprema" administración gubernamental, primero, y de las necesidades industriales, comerciales y financieras del país, en seguida (Anales, I.1., julio/1903: 1).

La ciencia servía "al capital”, que hacía que todos los preceptos éticos y científicos gravitaran bajo su órbita, como si se tratara de una implacable ley de la gravedad. Positivamente, había que superar "la apatía de los gobiernos pasados y las etapas revolucionarias" para recolectar "plantas indígenas" e iniciar su "estudio racional", lo cual crearía "fábricas en grande de productos químicos y medicinales” (Anales, I.2., agosto/1923: 63). La revolución industrial salvadoreña presupondría examen y utilización minuciosos de todos los recursos naturales.

Al estudio de la naturaleza y de lo humano, el museo no procedía con un propósito desinteresado y objetivo. Más bien, le concernía establecer un catálogo razonado de todos los productos naturales que se prestaran a un uso práctico y a su explotación comercial. Si la fundación del museo se debió al encomiable convencimiento del Estado por definir los intereses nacionales, su muestrario respondía a una utilidad comercial. Las exposiciones desplegaban solo aquellos productos que poseían una aplicación provechosa. Los que po- 
dían comercializarse en el extranjero eran aquellos especímenes vegetales y animales que merecían especial interés técnico.

Se impulsaban "exploraciones científicas" alrededor del territorio nacional; pero estas incursiones en el campo solo recolectaban lo que fuera financieramente ventajoso. La ciencia - natural y antropológica - era instrumento anodino de la expansión del capital y de un fin utilitario de lucro. Esta sumisión operativa, Guzmán la juzgaba necesaria para el desarrollo autosustentado del país. El saber científico y la política los dominaba una utilidad práctica y rentable.

Había que "dar a conocer en el exterior" - en el mercado global, diríamos ahora - "todo cuanto El Salvador tiene de rico, de explotable, de útil al progreso" (Anales, I.1., julio/1903: 37). Por esta razón comercial, se escribían múltiples reseñas sobre técnicas de explotación del bálsamo — de su resina medicinal y madera - sin percatarse de que en la región costera que lo abrigaba existía una población indígena (Anales, I.3., septiembre/1903: 81). Las "exploraciones científicas" en territorio nacional resaltaban la riqueza comercial de los productos naturales, a la vez que desdeñaban a la población indígena que los cultivaba.

En el ámbito lingüístico, por ejemplo, los Anales ni siquiera ofrecieron un somero vocabulario de términos náhuat; y el editor, por su parte, no rebasó la transcripción de breves muestras que citaba de viajeros extranjeros de mediados del siglo XIX (Guzmán, Apuntamientos, 1883: 447). Era obvio que los idiomas indígenas se hallaban más allá de cualquier comercialización. Carecían de valor monetario y la antropología salvadoreña podía ignorarlos. No había experiencia con el otro - ser-con (mit-sein) el otro-, ya que no se le reconocía su derecho a la palabra - a una lingüisticidad, verbum y ratio - tan expresiva y lógica como la hispana.

Más que del zoon logos ejon - animal dotado de lenguaje-Guzmán y sus contemporáneos derivaban su concepto de antropología de las ciencias naturales. En su tajante positivismo consideraban al hombre "químicamente" _ "agrupación molecular de materia" - , a la vez que acertaban en confirmar asuntos bíblicos (Anales, I.1., julio/1903: 15). "La fibra más sensible de nuestro corazón quizá formaba parte ha mucho tiempo de la organización de un vegetal de un país lejano", se aseguraba en el primer número (17). Nuestros más nobles sentimientos y creencias se percibían como vegetales espirituali- 
zados, que de la digestión se alzaban hacia las artes. Empero, tampoco prevalecía un espiritualismo materialista que se intuiría en el párrafo precedente. El verbo y razón indígenas - que enunciaran su interioridad e intervinieran en la vida en común - quedarían ocultos.

\section{Dinámica entre lo propio y lo ajeno}

Si Guzmán anhelaba "poner a Centro América en el camino de su transfiguración" civilizadora - "proteger la agricultura, artes e industrias nacionales"-, una paradoja económica afirmaba que este propósito solo se lograba al emular lo extraño. Hay que "copiar los modelos que nos ofrecen las grandes industrias" para que "dejemos de ser tributarios del extranjero en muchos artículos" (Anales, I.7., 1910: 277). Por un insólito juego especular, la identidad nacional modernizante la derivaba de la capacidad por absorber lo ajeno.

A Guzmán y su generación los afectaba un sentimiento de inferioridad, ya que una falta constituía lo salvadoreño por defecto al compararse con lo moderno: Europa y EE. UU. Salvar la brecha del retraso sería quehacer de la ciencia, la cual ayudaría a inculcarle al espíritu racial de "origen español” los "dones tan frecuentes entre los ingleses y los yankees" (Anales, I.2., agosto/1903: 47). "Tiempo es ya que imitemos el ejemplo de los anglo-sajones, que fríos razonadores se han consagrado a las artes útiles y a la explotación de las riquezas naturales tan prodigiosamente esparcidas por todos los ámbitos de nuestra América tropical" (Anales, I.2., agosto/1903: 73).

Pero "nuestra ardiente imaginación" se entregaba solo a "las bellas artes y la poesía" que la educación técnica lograría trasvasar en ideal práctico de progreso hacia "nuestra raza" embelesada en la contemplación estética sin utilidad. La contradicción se acentuaría de advertir que la producción nacional no aspiraba a abrir un mercado interno de consumo; en cambio, ante todo anhelaba ampliar su distribución global. La explotación de los vastos recursos naturales del trópico dependía de que los productos salvadoreños alcanzaran alta estima en el extranjero.

"Lo nuestro" y lo regional obedecían a modelos foráneos "progresivos" y a un régimen comercial globalizado. Los Anales no se cansaban de repetir "se venden en Europa muy bien [...] sirven en Europa y Estados Unidos" (Anales, I.6., diciembre/1903: 146). La identidad nacional la regía la utilidad co- 
mercial que a un "arte práctico" salvadoreño se le concedía en las metrópolis. Sólo importaba de lo propio aquello que lo ajeno le deparaba un alto valor de cambio y consumo. Para el progreso, se requería incluso el plagio de lo extranjero: "imitadores en nuestro país" (Anales, I.2., agosto/1903: 47). Una identidad nacional moderna implicaba "asimilar nuevos elementos de vida y de prosperidad", con el objetivo de no "rebajarse al nivel de los pueblos africanos" (Anales, I.6., diciembre/1903: 238).

Situado en el justo centro - entre lo primitivo-africano y lo civilizado-blanco-, lo hispano correría el peligro de deslizarse hacia la "rara fealdad" y "nivel moral desgraciadamente bajo" de lo zambo y negro o bien, por la ciencia, elevarse hacia lo prístino y racialmente blanco (Guzmán, Apuntamientos, 1883: 513). No otro era el desafío desarrollista y racial que enfrentaban Guzmán y su generación al promover la globalización industrial de El Salvador.

\section{Omisiones}

La más notable omisión la revelaría una perspectiva indigenista y de género, sin utilidad monetaria. Las actividades científicas y lucrativas el fundador del Museo las percibía como exclusivas de hombres con un distintivo carácter cultural: hispano-europeo. Si para la mujer los Anales imaginaban la creación de una moderna "Escuela de Economía Doméstica" - en su meta de cumplir la misión patriótica en el hogar - "vencido desde la conquista", para el indígena se vislumbraba su "impotencia” y "degeneración” (Anales, I.7., 1910: 294-298).

Describimos una breve reseña sobre el sitio que se le deparaba a la mujer, encerrada en el recinto doméstico, al igual que el desplazamiento histórico del indígena hacia lo pretérito y moribundo. Aún sin ofrecer un índice exhaustivo y estadísticas sobre autores y temáticas de los Anales, aseguramos ausencia (casi) total de escritoras y presencia de una mirada hispano-céntrica que exotiza lo indígena. Resultaba prueba irrefutable que la racionalidad técnica la realizaban solo "hombres de ciencia" (Anales, I.4., octubre/1903: 161).

\subsection{Género}

"Un servicio doméstico inteligente y bien dirigido" presuponía que el propio "señor Ministro de Instrucción Pública" aplicara el rigor de la ciencia en la 
formación técnica de la mujer para cuidar "el santuario del hogar" (Anales, I.7., 1910: 294-298). Era inútil que la fémina ocupara "las funciones sociales más honoríficas" si "se descuidan los quehaceres domésticos". Como legislador, Guzmán no imaginaba la posibilidad de compartir un trabajo cotidiano. Más bien, su proyecto científico de nación se enfocaba hacia el "cumplimiento [estricto] de esas obligaciones" que le pertenecían de lleno al entorno femenino. "Las labores domésticas [...] debe la mujer hacendosa desempeñarlas en cuanto su tiempo se lo permita y lo reclamen también las necesidades del hogar". Negarse a ello significa — en el caso de la mujer, no del hombre"necedad o pereza".

Aún si la misma reseña incitaba al "espíritu serio y filosófico" — del hombre, por supuesto - a considerar que "la mujer" no era el único objeto de placer estético, su "bella" presencia se requería a la hora de evaluar una "exposición nacional", como aderezo a la de la "selecta sociedad" (Anales, I.4., octubre/1903: 135). Si la nueva sensibilidad científica consideraba que "la belleza no sólo se encuentra en el rostro de las mujeres [sino] existe en todo lo que nos rodea", el despliegue de resultados científicos necesitaba de su concurrencia. "Asistieron nuestras altas clases sociales de esta capital y departamentos, y en particular el bello sexo salvadoreño" (Anales, I.10., diciembre/1904: 486). La ciencia dejaría de proponer simples juicios analíticos, para endulzarse gracias a la distinción social que proponía su ejercicio y exhibición, así como a los atractivos de recrear la mirada masculina ante "el bello sexo".

Frente al peligro que la mujer le disputara al hombre posiciones influyentes, al estado liberal le concernía asegurarse de que la fémina cumpliera "los sagrados deberes" de "hija, esposa y madre" (295). En cronología evolutiva, estos quehaceres mujeriles no se visualizaban como un simple trabajo. Representaban una esfera que Guzmán y sus contemporáneos llamaban un “arte”, la cual les reservaban a cónyuges y criadas.

\subsection{Etnicidad}

La etnografía que exaltaba la noble descendencia "egipcia" e "israelita" de mayas, pipiles y aztecas, comprobaba el agotamiento actual de cualquier otra raza y cultura centroamericana distinta de la española castiza o, en su defecto, de la europea ("Etnología", Anales, I.3., septiembre/1913: 108-112). El estudio etnográfico del pasado era excusa para asentar el predominio político hispánico sobre otras culturas y razas centroamericanas "inferiores". 
Lo indígena se visualizaba siempre como "antigüedades [...] precolombinas" (Anales, I.7., 1904: 286). Esta remisión de "artes y cultura de nuestros aborígenes - 'primitiva raza' - hacia lo pretérito acentuaba la modernidad progresiva de lo hispanoamericano (lugar citado y 317). Desde Guatemala se auguraba que "su decadencia posterior sabemos a qué debe atribuirse [al hecho de ser] razas vencidas y sujetas [...] y así seguirán hasta que se confundan o se acaben" (J. Rodríguez Luna, Anales, 2.14., septiembre/1905: 741). Entre los ideales modernizadores del Museo se contaba con el acabamiento y supresión de lo indígena.

El breve artículo "Etnología" (Anales, I.3., septiembre/1903: 108-112) resultaría suficiente para evaluar el lapso de racionalidad que separa las clasificaciones botánicas y zoológicas de las humanas. Si fauna y flora Guzmán las observa bajo un prisma de creciente rigor taxonómico, a su conciudadano indígena lo imagina en contacto con el Mediterráneo antiguo. Por ficción crédula, existía "comercio global” entre los egipcios y la Costa del Bálsamo en el Pacífico salvadoreño.

Como siempre, según expresión ingenua, se recurría a 'hechos' que 'hablan por sí mismos' al demostrar semejanzas del Egipto antiguo con el continente americano. En lo que consideraba 'cientificidad acertada', Guzmán sólo exponía la evidencia irrefutable con claridad necesaria. Mientras que para el estudio de plantas y animales útiles recurría a métodos químicos y biológicos modernos, para el antropológico se conformaba con leer la Biblia y documentos similares, para comprobar la antigua raigambre indígena en el Viejo Mundo.

Así, líderes indígenas participaron en la construcción de la "torre de Babel” y viajaron por Babilonia. Escondieron "tesoros de la antigua gentilidad india" en el "Soconuzco". "Las naciones que compusieron el imperio mexicano pertenecían a la descendencia de Nephtuin que salió de Egipto", y el paradigma de la civilización mesoamericana - los toltecas - "eran de la casa de Israel", a quienes "el profeta Moisés sacó del cautiverio en que los tenía Faraón”.

Prueba de esa liberación Guzmán la encontraba en "la intolerancia de Moisés", quien "quiso trasladar[los] a las riberas del mar Bermejo [golfo de California] que hoy es parte de la República Mexicana”. Quimeras mitológicas — disfrazadas de ciencia - poblaban las teorías históricas de Guzmán. Desde su perspectiva "científica", la ficción novelesca ofrecía hechos palpables. Las 
acusaciones que su espíritu de biólogo dirigía contra escritores se revertían en espejeo hacia su escritura de la historia. "Creer que la Botánica, en el sentido literario, es una prosaica representación de la vida estética, es una ignorancia imperdonable a poetas y literatos" (Guzmán, Especies, 1924: 8).

Esta correspondencia cultural podría juzgarse positiva -indígenas tan civilizados como egipcios, israelitas, etc. - si no fuera porque un determinismo geográfico - también teoría 'científica', por supuesto - demostraba que "la obra bienhechora" de la antigüedad clásica había decaído por la influencia del clima. Hasta los pueblos más desarrollados — "extranjeros del Norte de Europa, ingleses, alemanes, franceses, holandeses, etc." - al "llegar a nuestros países robustos y brotando de vida por todo su cuerpo [hemos visto que] a establecerse las costas y a poco tiempo degenerar, palidecer, enflaquecer..." (Anales, I.3., septiembre/1903: 124).

Acaso esa influencia climática - aunada al espíritu de conquista - hacía que el despegue de la antropología salvadoreña visualizara a los indígenas como "raza decadente" e informe, afectada también por clima impío y la sumisión colonial (Guzmán, Apuntamientos, 1883: 505). La caracterización guzmaniana culmina en el asombro que contrapone gloria pretérita con decadencia presente. "¿Qué contraste! Quién al meditar sobre las hermosas ruinas de sus antiguas ciudades podría reconocer en estos restos de aquella civilización el poder de una raza que yace sepultada en la noche del olvido", cuyo único destino lo señalaba la consumación. (Guzmán, Apuntamientos, 1883: 505).

\section{Migración neocolonial}

Ante este descalabro poblacional, el ideal demográfico de Guzmán implantaría una política migratoria que atraería colonos europeos "del Mediodía" - activos y laboriosos - para sustituir a nativos, a sus ojos, soñolientos y decadentes. La figura racial europea haría del trópico - perezoso y durmiente - una utopía agrícola-industrial, cuyo modelo nacional lo ofrecía Bélgica (Anales, marzo/1906, 16: 853). El desarrollo no solo lo dictaría la técnica ni la economía. Lo decretaría una transmutación racial y étnica del país.

Los naciones independientes propiciarían una nueva "colonización que afianzara su progreso". Desde finales del siglo XIX, Guzmán recomendaba que "la colonización e inmigración extranjera [...] es una de las más sólidas y seguras 
bases en que debe apoyarse la prosperidad y desarrollo de la riqueza en estas florecientes y vírgenes comarcas de la América Central" (Guzmán, Apuntamientos, 1883: 405). A lo que la actualidad visualizaría como transferencia de capital y tecnología, científicamente, Guzmán agregaba "la importancia de la inmigración en relación con el desarrollo de la riqueza pública” (1883: 417).

Obviamente, este traspaso demográfico sería selectivo, ya que "el europeo de Mediodía se hallará notablemente bien en nuestras latitudes, mientras que el negro africano llevará una existencia enfermiza" (Guzmán, Apuntamientos, 1883: 407). La antropología culminaba con recomendaciones para que el gobierno promoviera una vasta política diplomática por "la inmigración de activos e industriosos colonos" (Guzmán, Apuntamientos, 1883: 417). Guzmán había comprobado que existían correlaciones directas entre raza - indialadina/mestiza-blanca - y clase social, las cuales presuponían que, junto a un blanqueamiento, una "fusión de razas" fomentaría el desarrollo (Guzmán, Apuntamientos, 1883: 516). Más aún, la secuencia racial antedicha se correspondía con el transcurso evolutivo de la humanidad.

Lo que la actualidad percibe en términos sociológicos estrictos - disparidad económica, pobreza y poder político - en Guzmán se revestía también de un carácter biológico-racial irremisible. El único "porvenir de la raza india" lo auguraba su disolución (Guzmán, Apuntamientos, 1883: 517). "La paz, trabajo y libertad" que el gobierno propiciaba por la creación de escuelas no bastarían para elevar la "raza india". A este indiscutible quehacer gubernamental - que actualizaba el apostolado lascaciano - era necesario añadir su "incorporación forzosa en el gran movimiento civilizatorio del siglo" (517). El transvase biológico-racial - fusión con la raza criolla o con la ladina - resultaba una acción tan necesaria como la educativa y social. Blanqueado, al indígena se le vaticinaba un progreso certero y creciente.

\section{Conclusión}

Confinamiento de "la mujer hacendosa" en "las labores domésticas" — del indígena en su grandeza pretérita - encaminaría al hombre hispano moderno hacia un progreso similar al de los países civilizados y pujantes: anglo-americanos y europeos. Acaso por la sumisión de la ciencia social a designios gubernamentales y comerciales, a diferencia de México y Francia, en El Salvador nunca se fundó un "colegio de altos estudios" con suficiente autonomía 
para conducir investigaciones científicas y antropológicas de largo alcance. La labor del Museo Nacional, los Anales y el pensamiento de Guzmán nos informan por qué en el país se vuelve tan difícil inculcar un pensamiento crítico laico, más allá del tributo que se profesa por los regentes del orden universal: "supremo Estado" y "capital".

Por paradoja nacionalista, quien por décadas le otorgó su nombre al actual Museo Nacional de Antropología (Muna), carecía de una visión en defensa del indígena y percibía sus costumbres como "antipatrióticas", ya que promovían "tierras del común" - autorizadas por la Corona española-, las cuales atentaban contra el principio "eterno" de la propiedad privada, cuya "consecuencia necesaria" es la "idea" misma de "patria" (Guzmán, 1914: 141, 167 y 194). Acaso este emblema caracterice la singularidad salvadoreña - al menos en la esfera antropológica - como un país sin instituciones indigenistas sólidas y cuyo máximo lugar de expresión, para las culturas a las cuales representaría, lo patrocina el ideal anti-indigenista por disolverlo.

Según los Anales del Museo Nacional, sin embargo, el objetivo de una institución tal jamás consistiría en abrir espacios para expresar una diversidad étnica nacional, la cual debía extirparse. "El Museo Nacional no es un establecimiento destinado a coleccionar objetos curiosos [como la cultura indígena actual] o destinados a estudios teóricos sobre Ciencias Naturales o Biológicas, sino un centro destinado a dar las más grandes amplitudes a la riqueza nacional"; por eso, como en EU. UU. lo patrocinarían "el Gobierno y los grandes propietarios y comerciantes (Anales, I.3., septiembre/1903: 82). En la actualidad, no nos extrañaría que el Muna - continuador del legado guzmaniano - solo visualice al indígena en lo arqueológico - glorioso, pretérito y difunto - mientras, cara a cara, le niega a nuestros contemporáneos el derecho a la representación.

\section{Bibliografía mínima de David J. Guzmán}

Guzmán, David J., Obras escogidas. San Salvador: Dirección de Publicaciones e Impresos, 2000. Carlos Castro (Ed.).

Especies útiles de la flora salvadoreña médico-industrial: con aplicación a la medicina, farmacia, agricultura, artes, industria y comercio/. San Salvador: Ministerio de Educación, Dirección de Publicaciones, 1980.

Nuevo método para leer y declamar correctamente: para Escuelas Primarias Superiores e Institutos de Enseñanza Secundaria y Normal; complemento del Prontuario de locución, 
estilo, declamación y elocuencia; principios fundamentales de la palabra /. San Salvador: Revista del Ateneo, 1923.

Fitopatología; estudio de las enfermedades que afectan a las plantas agrícolas de El Salvador. San Salvador: Imprenta Nacional, 1919

Laboratorio de patología vegetal: Parte primera, plagas de la agricultura /. San Salvador: Imprenta Nacional, 1919.

Prontuario de alocución, estilo, declamación y elocuencia: Vade-mecum del orador salvadoreño /. San Salvador: [s.n.], 1915.

Comentarios sobre instrucción cívica y moral práctica y social. San Salvador: Imprenta Nacional, 1914

Catálogo de los artículos del departamento tecnológico. San Salvador: Museo Nacional "Dr. David J. Guzmán", 1910.

Catálogo analítico y general de los objetos que El Salvador presenta en la Exposición nacional de 1904 /. San Salvador, 1904.

Cartilla de agricultura para uso de las escuelas primarias de la República /. San Salvador: Imprenta Nacional, 1903.

Anales, Órgano Oficial del Instituto del Mismo Nombre. 1903-1911.

Reglamento del Museo Científico, Agrícola e Industrial de El Salvador. San Salvador: Museo

Nacional "David J. Guzmán.” 1902.

Catálogo oficial de los productos que la Republica del Salvador envía a la Exposición International de Paris de 1889 con un cuadro estadístico é historial de todas estas producciones por David J. Guzmán. San Salvador: Imprenta Nacional, 1888.

Catálogo oficial de los productos que la República del Salvador envía a la Exposición Internacional de Paris de 1889. San Salvador: Imprenta Nacional, 1888.

Catálogo oficial de los productos ... con un cuadro estadístico é historial de todas estas producciones /. San Salvador: Imprenta Nacional, 1888.

Concurso pedagógico de 1887 : De la organización de la Instrucción Primaria en El Salvador /. San Salvador: Imprenta Nacional, 1886.

De la organización de la instrucción primaria en el Salvador. San Salvador: Imprenta Nacional, 1886.

Apuntamientos sobre la topografía física de la República del Salvador, comprendiendo: su historia natural, sus producciones, industria, comercio e inmigración, climas, estadística \&. San Salvador, Tipografía de "El Cometa", 1883.

Exposición Universal de Chile: Catálogo del Salvador/. San Salvador: Tipografía Nacional, 1875 .

Cerna Chavarría, Efraín.; Guzmán, David J.; Velásquez, José Humberto. Materiales para el estudio de David J. Guzmán /. San Salvador: S/n, 1979. 


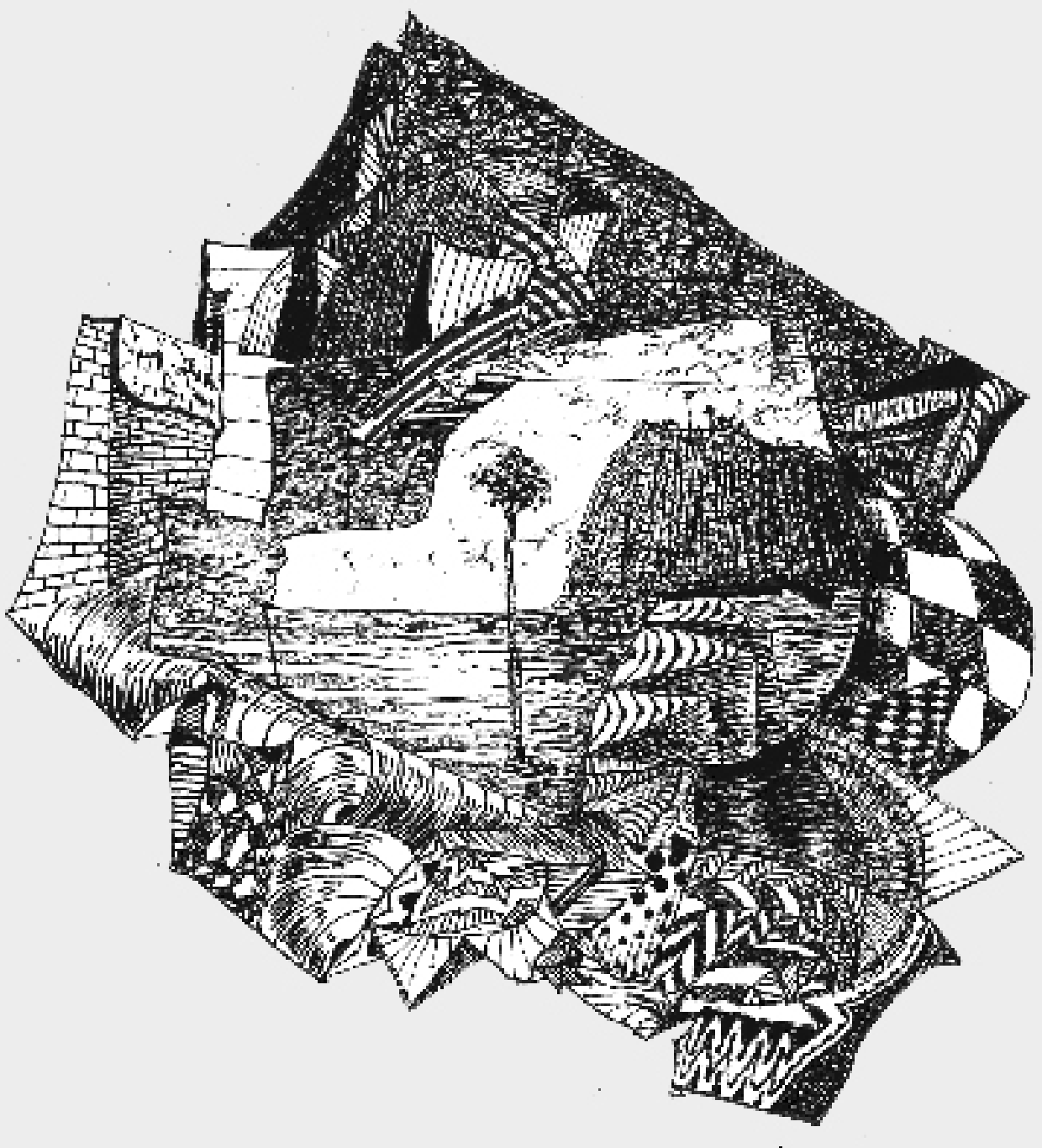




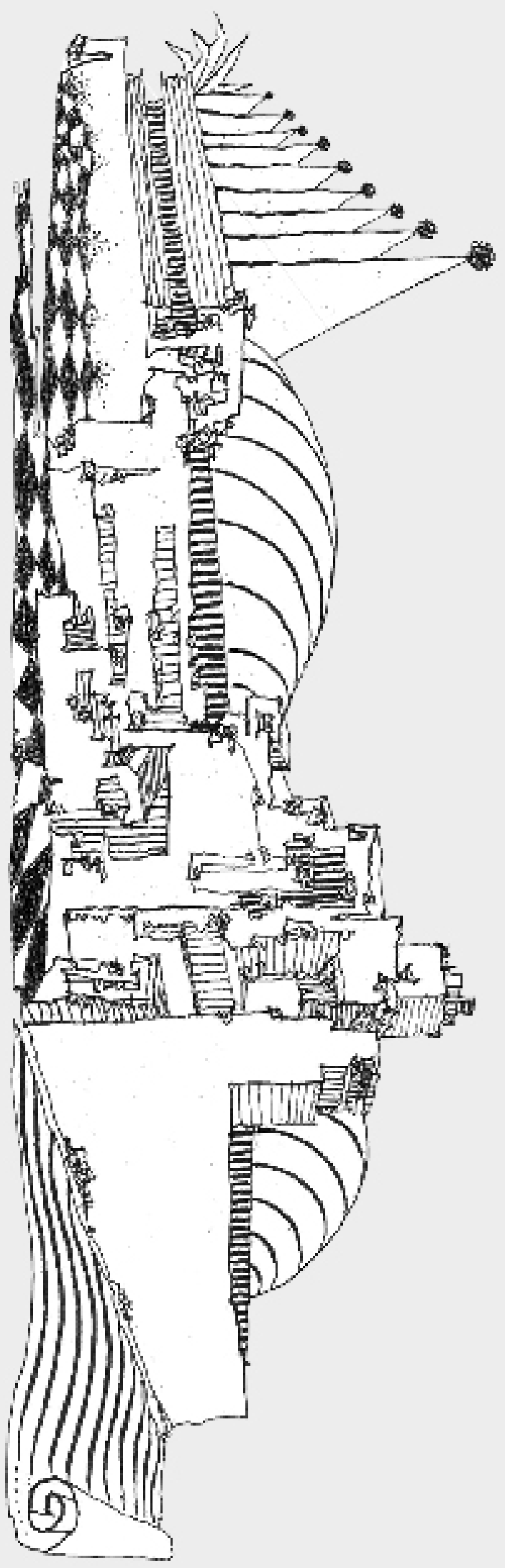

